\title{
Effects of the heating process of soybean oil and seeds on fatty acid biohydrogenation in vitro
}

\author{
A. Troegeler-Meynadier, ${ }^{*} \dagger \ddagger^{1}$ S. Puaut, ${ }^{*} \dagger \ddagger$ Y. Farizon, ${ }^{*} \dagger \ddagger$ and F. Enjalbert ${ }^{*} \dagger \ddagger$ \\ *Université de Toulouse INPT ENVT, UMR1289 Tissus Animaux Nutrition Digestion Ecosystème et Métabolisme, F-31076 Toulouse, France \\ †INRA, UMR1289 Tissus Animaux Nutrition Digestion Ecosystème et Métabolisme, F-31326 Castanet-Tolosan, France \\ łUniversité de Toulouse INPT ENSAT, UMR1289 Tissus Animaux Nutrition Digestion Ecosystème et Métabolisme, F-31326 Castanet-Tolosan, \\ France
}

\section{ABSTRACT}

Heating fat is an efficient way to alter ruminal biohydrogenation $(\mathrm{BH})$ and milk fat quality. Nevertheless, results are variable among studies and this could be due to various heating conditions differently affecting $\mathrm{BH}$. The objectives of this study were to determine the effect of type and duration of heating of soybean oil or seeds on $\mathrm{BH}$ in vitro. Ruminal content cultures were incubated to first investigate the effects of roasting duration (no heating, and 0.5- and 6-h roasting) at $125^{\circ} \mathrm{C}$ and its interaction with fat source (soybean seeds vs. soybean oil), focusing on linoleic acid $\mathrm{BH}$ and its intermediates: conjugated linoleic acid (CLA) and trans-C18:1. Additionally, we compared the effects of seed extrusion with the 6 combinations of unheated and roasted oils and seeds. None of the treatments was efficient to protect linoleic acid from BH. Soybean oil resulted in higher trans-11 isomer production than seeds: 5.7 and 1.2 times higher for cis-9,trans-11 CLA and trans-11 $\mathrm{C} 18: 1$, respectively. A $125^{\circ} \mathrm{C}, 0.5$-h roasting increased trans-11 isomer production by $11 \%$ compared with no heating and 6-h roasted fat. Extrusion of seeds was more efficient to increase trans-11 C18:1 production than seed roasting, leading to values similar to oils. For other fatty acids, including cis-9,trans-11 CLA, extrusion resulted in similar balances to seeds (mainly 0.5-h-roasted seeds). Extruded oilseeds would be more efficient than roasted seeds to produce trans-11 C18:1; nevertheless, effects of conditions of extrusion need to be explored.

Key words: ruminal biohydrogenation, roasting, extrusion, trans fatty acid

\section{INTRODUCTION}

Conjugated linoleic acid is a collective term for positional and geometrical isomers of linoleic acid (cis-

Received November 29, 2013.

Accepted May 19, 2014.

${ }^{1}$ Corresponding author: a.troegeler@envt.fr 9,cis-12 C18:2) with conjugated double bonds, which have been reported to prevent some diseases, such as cancer, obesity, and arteriosclerosis (Troegeler-Meynadier and Enjalbert, 2005). Many human foods contain CLA, dairy products having the highest concentrations. In dairy cows, milk CLA have 2 origins. The first is their formation during ruminal biohydrogenation (BH) of cis-9,cis-12 C18:2, which begins with an isomerization, mediated by several bacterial isomerases, leading to several CLA isomers, mainly $\Delta^{12}$-isomerase and $\Delta^{9}$-isomerase, which produce cis-9,trans-11 CLA and trans-10,cis-12 CLA, respectively. Thereafter, an initial reduction produces different trans-octadecenoic acid (trans C18:1) isomers, including trans-11 C18:1 (vaccenic acid) and trans-10 C18:1 from the abovementioned CLA isomers, respectively. Finally, a subsequent reduction produces stearic acid (C18:0). If bacteria responsible for the trans-10 pathway are still debated, trans-11 isomers are known to be produced by fibrolytic bacteria from the Butyrivibrio group, among which only Butyrivibrio proteoclasticus and Butyrivibrio hungatei are able to form stearic acid (Paillard et al., 2007). Due to its rapid reduction, very little CLA flows out of the rumen, implying that ruminal origin is of minor importance for milk CLA. The second origin that produces the most milk CLA is the mammary desaturation of trans-11 C18:1 into cis-9,trans 11-CLA (Griinari et al., 2000); trans-11 C18:1 is an intermediate of ruminal $\mathrm{BH}$ of both cis-9,cis-12 C18:2 and $\alpha$-linolenic acid (cis9,cis-12,cis-15 C18:3). Thus, milk CLA content could be modulated by both factors affecting cis-9, cis-12 $\mathrm{C} 18: 2$ and cis-9,cis-12,cis-15 C18:3 BH and factors affecting desaturation in the mammary gland.

One way to efficiently increase CLA milk concentrations is the addition of fat supplements to the dairy cow diet, particularly fat rich in cis-9, cis-12 C18:2 or cis-9,cis-12,cis-15 C18:3 (Troegeler-Meynadier et al., 2007; Chilliard et al., 2009). In the dairy cow diet, fat is usually carried out by oilseeds, which are often heated; for example, by roasting or extrusion. These processes have been shown to have variable effects on $\mathrm{BH}$ among studies, which need to be specified and 
explained: heated oilseeds often induced a decrease in cis-9,cis-12 $\mathrm{C} 18: 2$ and cis-9,cis-12,cis-15 $\mathrm{C} 18: 3 \mathrm{BH}$ in vivo (Gonthier et al., 2005), in situ (Chouinard et al., 1997b; Troegeler-Meynadier et al., 2006b), and in vitro (Reddy et al., 1994); however, this partial protection of PUFA against $\mathrm{BH}$ was not always noticed (Akraim et al., 2006; Neves et al., 2007; Abdi et al., 2013). Moreover, in most of these studies, heat treatments resulted in an accumulation of $\mathrm{BH}$ intermediates, particularly cis-9,trans-11 CLA or trans-11 C18:1, or both. This increase in $\mathrm{BH}$ intermediates was more important with extruded than roasted soybeans in the experiment of McNiven et al. (2004), and Troegeler-Meynadier et al. (2006b) showed in situ a 5 times higher CLA production with extruded than roasted soybean seeds for the same heating temperature (i.e., $150^{\circ} \mathrm{C}$ ). Such an effect of extrusion could be due to better availability of fat because of the rupture of cell membranes caused by this process (Reddy et al., 1994).

On the other hand, a previous study in our laboratory (Privé et al., 2010; Kaleem et al., 2013b) showed that lipid oxidative compounds could, at least in part, be responsible for the modifications of PUFA ruminal $\mathrm{BH}$ in vitro, and that protection of PUFA was probably linked to heating temperature. Nevertheless, in the study of Privé et al. (2010), increasing duration and temperature of oil heating increased trans-10 isomers and decreased trans-11 isomers, contrary to in vivo or in situ observations with roasted or extruded oilseeds (Gonthier et al., 2005; Akraim et al., 2006; TroegelerMeynadier et al., 2006b).

Therefore, we made the following assumptions regarding the various effects of heated fat on $\mathrm{BH}$ observed in previous cited studies: (1) the effects of heating depend on fat source (oil vs. oilseeds); (2) the effects of extrusion could be, in part, effects of oil heating, as this process provokes a release of fat from vegetal cells, and effects of seeds heating, as other seed components than oil can be altered by heating. The objectives of this study were to investigate in vitro the effects on $\mathrm{BH}$ of (1) duration of heating and its interaction with fat source, and (2) type of heating by comparing unheated and roasted oil and soybeans with extruded soybeans. Such experiments would allow to ascertain the effects of thermal treatment on $\mathrm{BH}$ reactions and intermediates, and to provide some explanations about these effects.

\section{MATERIALS AND METHODS}

In vitro ruminal cultures were used to evaluate the effects on $\mathrm{BH}$ of (1) heating duration and its interaction with source of fat by comparing unheated and 0.5 - and 6 -h-roasted soybean oils and seeds in a $3 \times 2$ arrangement, and (2) type of thermal treatment (unheated and 0.5 - and 6-h roasted seeds and oils vs. extrusion for soybean seeds only).

\section{Preparation of Fats}

A batch of soybean seeds (Valorex SAS, Combourtillé, France) was used for roasting and extrusion. The extrusion process of ground (6-mm screen) soybean seeds consisted of 30-min preconditioning with a temperature program from 95 to $55^{\circ} \mathrm{C}$ lasting $30 \mathrm{~min}$, followed by extrusion at $125^{\circ} \mathrm{C}$ for 30 to $60 \mathrm{~s}$. Thereafter, extruded seeds were ground (1-mm screen) for in vitro incubations. Roasted seeds and soybean oil (Intermarché, Toulouse, France) were obtained by heating ground (1$\mathrm{mm}$ screen) seeds and oil at $125^{\circ} \mathrm{C}$ for 0.5 or $6 \mathrm{~h}$ (i.e., the same temperature as for extrusion). All fat sources were then frozen at $-80^{\circ} \mathrm{C}$ until utilization. The treatments were designated as unheated oil, 0.5 -h roasted oil, 6 -h roasted oil, unheated seeds, 0.5 -h roasted seeds, 6 -h roasted seeds, and extruded seeds. Their respective unsaturated FA contents are presented in Table 1.

\section{In Vitro Cultures}

Ruminal incubations were performed in a water bath rotary shaker (Aquatron; Infors AG, Bottmingen, Switzerland). Ruminal fluid was obtained from a fistulated nonlactating Holstein cow receiving $10 \mathrm{~kg}$ of DM of a

Table 1. Unsaturated FA content (g/100 g) and peroxide values (PV; $\mathrm{mEq} / \mathrm{kg}$ of fat) of soybean meal, soybean oils, and soybean seeds

\begin{tabular}{|c|c|c|c|c|c|c|c|c|}
\hline \multirow[b]{3}{*}{ Item } & \multirow{3}{*}{$\begin{array}{c}\text { Soybean } \\
\text { meal }\end{array}$} & \multicolumn{3}{|c|}{ Soybean oil } & \multicolumn{4}{|c|}{ Soybean seeds } \\
\hline & & \multirow[b]{2}{*}{ Unheated } & \multicolumn{2}{|c|}{ Roasted } & \multirow[b]{2}{*}{ Unheated } & \multicolumn{2}{|c|}{ Roasted } & \multirow[b]{2}{*}{ Extruded } \\
\hline & & & $0.5 \mathrm{~h}$ & $6 \mathrm{~h}$ & & $0.5 \mathrm{~h}$ & $6 \mathrm{~h}$ & \\
\hline cis-9 C18: $1^{1}$ & 0.35 & 19.07 & 18.50 & 18.83 & 3.11 & 3.51 & 3.65 & 3.06 \\
\hline cis-9,cis-12 C18:2 $2^{1}$ & 1.25 & 50.47 & 48.88 & 49.11 & 10.25 & 11.24 & 11.62 & 8.40 \\
\hline cis-9,cis-12,cis-15 C18:3 ${ }^{1}$ & 0.14 & 7.29 & 7.05 & 6.97 & 1.71 & 1.84 & 1.82 & 1.60 \\
\hline $\mathrm{PV}^{2}$ & - & 6.72 & 9.33 & 56.56 & 4.16 & 4.94 & 46.06 & 29.34 \\
\hline
\end{tabular}

${ }^{1}$ Single determination.

${ }^{2}$ Three determinations. 
$60 \%$ concentrate diet $(38.6 \%$ corn silage, $6.8 \%$ soybean meal, $34.8 \%$ ground corn, $17.9 \%$ extruded seeds, and $1.9 \%$ mineral and vitamin supplement, on a DM basis) in 2 equal meals. The cow was adapted to this diet for 2 wk before the beginning of the experiment. Rumen fluid was taken from the cow with a vacuum pump before morning feeding and strained through a metal sieve (1.6-mm mesh). Rumen fluid was transferred quickly to the laboratory in anaerobic conditions and at $39^{\circ} \mathrm{C}$.

Eighty milliliters of strained ruminal fluid was poured into a 250-mL Erlenmeyer flask containing $100 \mathrm{mg}$ of oil plus $400 \mathrm{mg}$ of ground (1-mm) soybean meal or 500 $\mathrm{mg}$ of soybeans, $2 \mathrm{~g}$ of ground (2-mm) meadow hay, and $0.5 \mathrm{~g}$ of ground $(1-\mathrm{mm})$ corn. Media were calculated to be isonitrogenous and isofibrous. Then, $80 \mathrm{~mL}$ of a bicarbonate buffer solution was added. The buffer solution composition (g/L) was as follows: $\mathrm{Na}_{2} \mathrm{HPO}_{4} \cdot 2 \mathrm{H}_{2} \mathrm{O}$ (19.5), $\mathrm{NaHCO}_{3}$ (9.24), $\mathrm{NaCl}$ (0.705); KCl (0.675), $\mathrm{CaCl}_{2} \cdot 2 \mathrm{H}_{2} \mathrm{O}$ (0.108), and $\mathrm{MgSO}_{4} \cdot 7 \mathrm{H}_{2} \mathrm{O}$ (0.180). The buffer solution was prewarmed at $39^{\circ} \mathrm{C}$ and saturated with $\mathrm{CO}_{2}$. The filled flasks were gassed with $\mathrm{CO}_{2}$ and placed in the water bath at $39^{\circ} \mathrm{C}$. Flasks were then closed with a rubber cap crossed by a plastic tube leading into the water to vent fermentation gas without oxygen entrance. Flasks were stirred at $130 \mathrm{rpm}$ and kept safe from the light during the 6-h incubation.

Two replicates of each treatment were incubated during each of the $3 \mathrm{~d}$ of culture, regrouped in 1 wk (i.e., a total of 6 replicates per treatment). Each day, 2 blanks without fat and not incubated were prepared to analyze the initial culture media. At the end of the incubation, fermentations were stopped by placing the flasks into iced water and the $\mathrm{pH}$ was measured. The contents of the flasks were then immediately frozen. Samples were freeze-dried (Virtis Freezemobile 25; Virtis Co. Inc., Gardiner, NY), weighed, ground, and homogenized in a ball mill (Dangoumau; Prolabo, Nogent-sur-Marne, France) and kept at $-18^{\circ} \mathrm{C}$ for later analysis.

\section{FA and Peroxides Analysis}

The degree of oxidation of oils was estimated by the peroxide value (PV; AFNOR, 2004), which was expressed as milliequivalents of $\mathrm{O}_{2}$ per kilogram of fat.

The FA of unheated fat, heated fat, blanks and incubated media were extracted and methylated in situ using the procedure of Sukhija and Palmquist (1988), modified according to Jenkins (2010). Nonadecanoic acid (C19:0) was used as the internal standard at a dose of $0.8 \mathrm{mg}$. The FAME were then quantified by gas chromatography (Agilent 6890N, equipped with a model 7683 autoinjector, network GC System; Agilent
Technologies Inc., Palo Alto, CA), using a fused silica capillary column (CPSil88; $100 \mathrm{~m} \times 0.25 \mathrm{~mm}$ i.d., $0.20-\mu \mathrm{m}$ film thickness; Varian BV, Middelburg, the Netherlands).

For analysis, the flame ionization detector temperature was maintained at $260^{\circ} \mathrm{C}$ and the injector at $255^{\circ} \mathrm{C}$; the split ratio was 1:50. Hydrogen was the carrier gas, with a constant flow of $1 \mathrm{~mL} / \mathrm{min}$. The samples were injected in $1 \mu \mathrm{L}$ of hexane. The initial temperature of the oven was $60^{\circ} \mathrm{C}$, held for $2 \mathrm{~min}$, increased by $8^{\circ} \mathrm{C} /$ min to $150^{\circ} \mathrm{C}$, held at $150^{\circ} \mathrm{C}$ for $12 \mathrm{~min}$, increased by $2^{\circ} \mathrm{C} / \mathrm{min}$ to $175^{\circ} \mathrm{C}$, held at $175^{\circ} \mathrm{C}$ for $20 \mathrm{~min}$, increased by $5^{\circ} \mathrm{C} / \mathrm{min}$ to $225^{\circ} \mathrm{C}$, held at $225^{\circ} \mathrm{C}$ for $10 \mathrm{~min}$, and increased by $5^{\circ} \mathrm{C} / \mathrm{min}$ to a final temperature of $240^{\circ} \mathrm{C}$ and maintained at $240^{\circ} \mathrm{C}$ for $10 \mathrm{~min}$. This temperature program allowed the separation of cis-15 C18:1 from C19:0, but did not allow the separation of cis-9,cis12,cis-15 C18:3 from C20:1 and of trans-13+14 from cis-9 C18:1. Hence, a second temperature program was used to separate these FA. For this analysis, the flame ionization detector temperature was maintained at $260^{\circ} \mathrm{C}$ and the injector at $255^{\circ} \mathrm{C}$; the split ratio was 1:50. Hydrogen was the carrier gas, with a constant pressure of $150 \mathrm{kPa}$. The samples were injected in 1 $\mu \mathrm{L}$ of hexane. The initial temperature of the oven was $60^{\circ} \mathrm{C}$, which was held for $3 \mathrm{~min}$, increased by $8^{\circ} \mathrm{C} / \mathrm{min}$ to $190^{\circ} \mathrm{C}$, held at $190^{\circ} \mathrm{C}$ for $13 \mathrm{~min}$, increased by $5^{\circ} \mathrm{C} /$ min to $225^{\circ} \mathrm{C}$, held at $225^{\circ} \mathrm{C}$ for $10 \mathrm{~min}$, and increased by $10^{\circ} \mathrm{C} / \mathrm{min}$ to a final temperature of $230^{\circ} \mathrm{C}$ maintained at $230^{\circ} \mathrm{C}$ for $1 \mathrm{~min}$. Peaks were identified and quantified by comparison with commercial standards (Sigma, St. Louis, MO), except C18:1 other than oleic acid (cis9 C18:1) and trans-9 and trans-11 C18:1, which were identified by order of elution. The FA concentrations were expressed as milligrams per kilogram of DM.

\section{Calculations}

Initial amounts of FA in cultures was calculated as the sum of FA contained in the blank plus that added by either $100 \mathrm{mg}$ of oil $+400 \mathrm{mg}$ of soybean meal or $500 \mathrm{mg}$ of roasted or extruded seeds. For each FA, production or disappearance was calculated as the amount in the incubated flask - (amount in blank + amount from added oil + soybean meal or oilseed).

The rates $(\mathrm{mg} / \mathrm{L}$ per hour) and efficiencies of the cis9,cis-12 C18:2 isomerization (v1 and E1, respectively), CLA reduction ( $\mathbf{v} 2$ and $\mathbf{E 2}$ ), and trans $\mathrm{C} 18: 1$ reduction (v3 and E3) were calculated as previously described by Troegeler-Meynadier et al. (2006a). Briefly, the global rate $(\mathrm{v})$ of a reaction was estimated by the disappearance rate of the substrate, and efficiency (E) of the reaction was estimated by the concentration of substrate 
disappeared during the incubation period divided by the total amounts of substrate available for the reaction.

$$
\begin{aligned}
\mathrm{v} 1= & ([\mathrm{C} 18: 2] \mathrm{b}-[\mathrm{C} 18: 2] \mathrm{e}) / 6, \text { with } 6 \\
& \text { being the incubation time; } \\
\mathrm{E} 1= & ([\mathrm{C} 18: 2] \mathrm{b}-[\mathrm{C} 18: 2] \mathrm{e}) /[\mathrm{C} 18: 2] \mathrm{b},
\end{aligned}
$$

where [C18:2]b and [C18:2]e represented the concentration of cis-9,cis-12 $\mathrm{C} 18: 2$ at the beginning and at the end of the 6-h incubation, respectively.

$$
\begin{gathered}
\mathrm{v} 2=([\mathrm{C} 18: 2] \mathrm{b}-[\mathrm{C} 18: 2] \mathrm{e}+[\mathrm{CLA}] \mathrm{b}-[\mathrm{CLA}] \mathrm{e}) / 6 \\
\mathrm{E} 2=([\mathrm{C} 18: 2] \mathrm{b}-[\mathrm{C} 18: 2] \mathrm{e}+[\mathrm{CLA}] \mathrm{b}- \\
[\mathrm{CLA}] \mathrm{e}) /([\mathrm{C} 18: 2] \mathrm{b}-[\mathrm{C} 18: 2] \mathrm{e}+[\mathrm{CLA}] \mathrm{b})
\end{gathered}
$$

where [CLA]b and [CLA]e represented the concentration of total CLA isomers measured at the beginning and at the end of the 6-h incubation, respectively.

$$
\begin{gathered}
\mathrm{v} 3=([\mathrm{C} 18: 2] \mathrm{b}-[\mathrm{C} 18: 2] \mathrm{e}+[\mathrm{C} 18: 3] \mathrm{b}-[\mathrm{C} 18: 3] \mathrm{e}+ \\
{[\mathrm{CLA}] \mathrm{b}-[\mathrm{CLA}] \mathrm{e}+[\mathrm{CLnA}] \mathrm{b}-[\mathrm{CLnA}] \mathrm{e}+[t-\mathrm{C} 18: 2]} \\
\mathrm{b}-[t-\mathrm{C} 18: 2] \mathrm{e}+[t-\mathrm{C} 18: 1] \mathrm{b}-[t-\mathrm{C} 18: 1] \mathrm{e}) / 6 ; \\
\mathrm{E} 3=([\mathrm{C} 18: 2] \mathrm{b}-[\mathrm{C} 18: 2] \mathrm{e}+[\mathrm{C} 18: 3] \mathrm{b}-[\mathrm{C} 18: 3] \mathrm{e} \\
+[\mathrm{CLA}] \mathrm{b}-[\mathrm{CLA}] \mathrm{e}+[\mathrm{CLnA}] \mathrm{b}-[\mathrm{CLnA}] \mathrm{e} \\
+[t-\mathrm{C} 18: 2] \mathrm{b}-[t-\mathrm{C} 18: 2] \mathrm{e}+[t-\mathrm{C} 18: 1] \mathrm{b}-[t-\mathrm{C} 18: 1] \mathrm{e}) / \\
\quad([\mathrm{C} 18: 2] \mathrm{b}-[\mathrm{C} 18: 2] \mathrm{e}+[\mathrm{C} 18: 3] \mathrm{b}-[\mathrm{C} 18: 3] \mathrm{e} \\
+[\mathrm{CLA}] \mathrm{b}-[\mathrm{CLA}] \mathrm{e}+[\mathrm{CLnA}] \mathrm{b}-[\mathrm{CLnA}] \mathrm{e} \\
+[t-\mathrm{C} 18: 2] \mathrm{b}-[t-\mathrm{C} 18: 2] \mathrm{e}+[t-\mathrm{C} 18: 1] \mathrm{b}),
\end{gathered}
$$

where $[t-\mathrm{C} 18: 1] \mathrm{b}$ and $[t-\mathrm{C} 18: 1] \mathrm{e}$ represented the concentration of total trans C18:1 isomers measured at the beginning and at the end of the 6 -h incubation period $\Delta \mathrm{t},[\mathrm{CLnA}] \mathrm{b}$ and $[\mathrm{CLnA}] \mathrm{e}$ those of conjugated linolenic acid (CLnA), and $[t-\mathrm{C} 18: 2] \mathrm{b}$ and $[t-\mathrm{C} 18: 2] \mathrm{e}$ those of trans-11,cis-15 C18:2, the 2 major intermediates of cis9,cis-12,cis-15 C18:3 BH. Although about 3\% of oleic acid can be isomerized to trans C18:1 (Mosley et al., 2002), all disappeared oleic acid was considered to be converted to C18:0.

\section{Data Analysis}

Fatty acid production or disappearance and rates and efficiencies of $\mathrm{BH}$ were analyzed using SYSTAT software (version 9; SPSS Inc., Chicago, IL) and were reported as mean values with standard error of the mean.

Because extrusion only applied to seeds, we performed 2 statistical analyses. Data relative to unheated and roasted oils and seeds were analyzed as a factorial design using the following model:

$$
\begin{gathered}
\text { variable }=\text { mean }+ \text { day of incubation effect } \\
+ \text { fat source effect }+ \text { roasting duration effect }+ \text { fat } \\
\text { source } \times \text { roasting duration interaction effect }+\varepsilon,
\end{gathered}
$$

with 3 levels for day of incubation, 2 levels for fat source (oils and seeds), 3 levels for roasting duration (no roasting, and 0.5 - and 6-h roasting), and $\varepsilon$ being the residual error.

For comparison of extruded seeds to other combinations of fat source and roasting durations, data relative to all treatments were analyzed using the following model:

$$
\begin{aligned}
\text { variable }= & \text { mean }+ \text { day of incubation effect } \\
& + \text { treatment effect }+\varepsilon,
\end{aligned}
$$

where the 7 treatments were unheated oil, 0.5 -h roasting oil and 6 -h roasting oil, unheated seeds, 0.5 -h roasting seeds, 6-h roasting seeds, and extruded seeds. All treatments were compared 2-by-2 using the Tukey test. Differences were considered significant at $P<0.05$.

\section{RESULTS}

Concerning $\mathrm{pH}$ values, initial and final average $\mathrm{pH}$ were 7.0 and 6.8, respectively, and no effect of treatments was observed ( $P=0.16$; results not shown).

\section{Initial Fat Composition of Cultures}

Unsaturated FA composition, PV of fat, and the initial FA amounts of the different culture media are presented in Tables 1 and 2. Peroxide values of unheated or 0.5 -h roasted fat sources were $<10 \mathrm{mEq} / \mathrm{kg}$, whereas PV of 6-h roasted fat sources and extruded seeds were 51 and $31 \mathrm{mEq} / \mathrm{kg}$ of fat, respectively. For the same roasting duration, seeds had a lower PV than oils. Cultures with added oil had the highest initial amount of cis-9 C18:1; those with unheated and roasted seeds had the highest initial amount of cis-9,cis-12,cis-15 C18:3. Cultures with extruded seeds had the lowest initial concentrations of cis-9, cis-12 C18:2. 
Table 2. Initial amount (mg/flask) of the major FA in the different cultures according to the heating process and roasting duration of soybean oil and seeds ${ }^{1}$

\begin{tabular}{|c|c|c|c|c|c|c|c|}
\hline FA (mg/flask) & \multicolumn{3}{|c|}{ Soybean oil } & \multicolumn{4}{|c|}{ Soybean seeds } \\
\hline C18:0 & 114.36 & 114.50 & 114.28 & 112.59 & 112.90 & 113.05 & 112.81 \\
\hline cis-9 C18:1 & 28.38 & 28.01 & 28.18 & 23.49 & 25.49 & 26.19 & 23.26 \\
\hline Total trans $\mathrm{C} 18: 1$ & 11.14 & 11.14 & 11.14 & 11.14 & 11.14 & 11.14 & 11.14 \\
\hline cis-9,cis-12,cis-15 C18:3 & 9.79 & 9.55 & 9.48 & 10.50 & 11.15 & 11.04 & 9.93 \\
\hline trans-10 isomers & 0.80 & 0.80 & 0.80 & 0.80 & 0.80 & 0.80 & 0.80 \\
\hline trans-11 isomers & 6.46 & 6.46 & 6.46 & 6.46 & 6.46 & 6.46 & 6.46 \\
\hline
\end{tabular}

${ }^{1}$ Six samples for each combination of fat source and treatment.

\section{Comparison of Soybean Oil to Soybean Seeds}

Tables 3 and 4 report the effects of fat source on C18 FA production and disappearance, and Table 5 reports kinetic parameters. Disappearances of cis-9, cis-12 C18:2 and cis-9 C18:1, either expressed as amounts or percentages, were significantly higher with oil than with seeds (Table 3). The disappeared quantity of cis-9, cis12,cis-15 C18:3 was higher with seeds than with oil, but the percentage of disappearance was higher with oil than with seeds.
The production of total CLA was 3.9 times higher with oil than with seeds, which was mainly due to cis9,trans-11 CLA $(\times 5.7)$, the major isomer (Table 4); production of other 9,11 CLA was also more important with oil than with seeds. Oils and seeds resulted in similar production of trans-10,cis-12 CLA. The production of trans-11,cis-15 C18:2, and those of total trans C18:1 (Table 3) and of all individual trans C18:1 isomers, except trans-10 C18:1 (Table 4), was higher with oil than with seeds. The production of total trans $\mathrm{C} 18: 1$ was 1.3 times higher with oil than with seeds. By contrast, the

Table 3. Effects of fat source and roasting duration on production (positive values) or disappearance (negative values) of FA (mg) and percentages of disappearance of oleic, linoleic, and $\alpha$-linolenic acids after 6 -h incubation with ruminal fluid, and comparison with extruded seeds ${ }^{1}$

\begin{tabular}{|c|c|c|c|c|c|c|c|c|c|c|c|}
\hline Item & \multicolumn{3}{|c|}{ Soybean oil } & \multicolumn{3}{|c|}{ Soybean seeds } & SEM & \multicolumn{3}{|c|}{$P$-value ${ }^{2}$} & $\begin{array}{l}\text { Extruded } \\
\text { soybeans }\end{array}$ \\
\hline \multicolumn{12}{|l|}{ FA balance (mg/flask) } \\
\hline C18:0 & 41.77 & $54.58^{*}$ & $48.37^{*}$ & 35.70 & $47.17^{*}$ & 39.27 & 2.325 & 0.03 & $<0.01$ & 0.54 & 38.31 \\
\hline cis-12 C18:1 & 0.11 & 0.13 & 0.13 & $0.09^{*}$ & 0.12 & 0.11 & 0.007 & $<0.01$ & $<0.01$ & 0.49 & 0.12 \\
\hline cis-15 C18:1 & 0.06 & 0.07 & 0.05 & 0.04 & 0.05 & 0.05 & 0.007 & $<0.01$ & 0.23 & 0.15 & 0.06 \\
\hline Total trans-C18:1 & 13.84 & 15.85 & 13.62 & $10.39^{*}$ & 12.94 & $11.26^{*}$ & 0.526 & $<0.01$ & $<0.01$ & 0.55 & 13.84 \\
\hline cis-9,cis-12 C18:2 & $-49.99^{*}$ & $-52.19 *$ & $-49.98^{*}$ & $-42.85^{*}$ & $-49.65^{*}$ & $-45.38^{*}$ & 1.013 & $<0.01$ & $<0.01$ & 0.03 & -38.94 \\
\hline Total CLA & $1.61^{*}$ & $1.42^{*}$ & $1.27^{*}$ & 0.30 & 0.43 & 0.37 & 0.090 & $<0.01$ & 0.12 & 0.07 & 0.58 \\
\hline trans-11,cis-15 C18:2 & 0.17 & $0.21^{*}$ & 0.14 & $0.01^{*}$ & $0.02^{*}$ & $0.02^{*}$ & 0.015 & $<0.01$ & 0.09 & 0.07 & 0.14 \\
\hline cis-9,cis-12,cis-15 C18:3 & -7.11 & -7.34 & -6.99 & -7.23 & $-8.10^{*}$ & -7.01 & 0.134 & $<0.01$ & $<0.01$ & $<0.01$ & -7.19 \\
\hline Sum of $\mathrm{UFA}^{3}$ & 67.88 & 72.97 & 69.22 & 61.23 & 67.58 & 60.13 & 1.597 & $<0.01$ & $<0.01$ & 0.37 & 65.90 \\
\hline
\end{tabular}

${ }^{1}$ Six replicates for each combination of fat source and treatment.

${ }^{2}$ Fat source $=$ unheated and roasted oils versus unheated and roasted seeds; roasting duration = unheated, and 0.5- and 6-h roasting; interaction $=$ fat source $\times$ roasting duration.

${ }^{3}$ Sum of unsaturated FA (UFA) $=$ cis-9 C18:1 + cis-9, cis-12 C18:2 + cis-9, cis-12,cis-15 C18:3.

* Significantly $(P<0.05)$ different from extruded seeds (Tukey test). 
Table 4. Effects of fat source and roasting duration on produced amounts (mg) of trans-C18:1 and CLA ${ }^{1}$ isomers after 6-h incubation with ruminal fluid, and comparison with extruded seeds ${ }^{1}$

\begin{tabular}{|c|c|c|c|c|c|c|c|c|c|c|c|}
\hline Item & \multicolumn{3}{|c|}{ Soybean oil } & \multicolumn{3}{|c|}{ Soybean seeds } & SEM & & & & $\begin{array}{l}\text { Extruded } \\
\text { soybeans }\end{array}$ \\
\hline \multicolumn{12}{|l|}{ trans $\mathrm{C} 18: 1$ isomer (mg/flask) } \\
\hline trans-4 C18:1 & 0.08 & 0.11 & 0.09 & $0.05^{*}$ & 0.07 & $0.05^{*}$ & 0.004 & $<0.01$ & $<0.01$ & 0.96 & 0.08 \\
\hline trans-9 C18:1 & 0.27 & $0.32^{*}$ & 0.30 & 0.22 & 0.27 & 0.22 & 0.015 & $<0.01$ & $<0.01$ & 0.38 & 0.26 \\
\hline trans-10 C18:1 & 0.43 & 0.54 & 0.54 & 0.47 & 0.59 & 0.40 & 0.044 & 0.89 & 0.02 & 0.04 & 0.45 \\
\hline trans-11 C18:1 & 10.34 & 11.59 & 9.95 & $8.31^{*}$ & 9.74 & $9.12^{*}$ & 0.348 & $<0.01$ & $<0.01$ & 0.26 & 10.73 \\
\hline trans-12 C18:1 & 0.62 & $0.76^{*}$ & $0.65^{*}$ & $0.35^{*}$ & 0.51 & $0.40^{*}$ & 0.033 & $<0.01$ & $<0.01$ & 0.98 & 0.53 \\
\hline trans-13+14 C18:1 & 0.77 & $1.29 *$ & 0.85 & $0.28^{*}$ & 0.58 & $0.24^{*}$ & 0.093 & $<0.01$ & $<0.01$ & 0.92 & 0.71 \\
\hline trans-15 C18:1 & 0.28 & $0.35^{*}$ & 0.21 & $0.02^{*}$ & 0.15 & $0.05^{*}$ & 0.033 & $<0.01$ & $<0.01$ & 0.21 & 0.18 \\
\hline trans-16 C18: $1^{3}$ & 0.51 & $0.66^{*}$ & 0.52 & $0.29^{*}$ & 0.51 & 0.37 & 0.037 & $<0.01$ & $<0.01$ & 0.65 & 0.42 \\
\hline \multicolumn{12}{|l|}{ CLA isomer (mg/flask) } \\
\hline \multicolumn{12}{|l|}{ Sum (mg/flask) } \\
\hline trans-10 isomers & 0.46 & 0.57 & 0.57 & 0.50 & 0.63 & 0.44 & 0.046 & 1.00 & 0.02 & 0.04 & 0.48 \\
\hline trans-11 isomers & 11.80 & 12.49 & 11.08 & $8.54^{*}$ & 10.08 & $9.40^{*}$ & 0.389 & $<0.01$ & $<0.01$ & 0.15 & 11.19 \\
\hline
\end{tabular}

${ }^{1}$ Six replicates for each combination of fat source and treatment.

${ }^{2}$ Fat source $=$ unheated and roasted oils versus unheated and roasted seeds; roasting duration $=$ unheated, and 0.5- and 6-h roasting; interaction $=$ fat source $\times$ roasting duration.

${ }^{3}$ Coeluted with cis-14 C18:1.

*Significantly $(P<0.05)$ different from extruded seeds (Tukey test).

production of cis-11 C18:1 was higher with seeds than with oil (Table 3). The production of C18:0 was higher with oil than with seeds.

The rate and the efficiency of isomerization, and the rate of CLA reduction were higher with oil, whereas the efficiencies of both reductions were higher with seeds (Table 5).

\section{Effects of Roasting Duration (No Heating, and 0.5- and 6-h Roasting)}

Effects of roasting are reported on Tables 3, 4, and 5 . Disappeared quantities and disappearance percentages of cis-9 C18:1, cis-9,cis-12 C18:2, and cis-9,cis-12,cis-15 C18:3 were higher for 0.5 -h roasting than for unheated

Table 5. Effects of fat source and roasting duration on rates (v; mg/L per hour) and efficiencies (E; \%) of the 3 reactions of linoleic acid biohydrogenation $^{1}$ in 6 -h incubation with ruminal fluid, and comparison with extruded seeds ${ }^{1}$

\begin{tabular}{|c|c|c|c|c|c|c|c|c|c|c|c|}
\hline Item $^{2}$ & \multicolumn{3}{|c|}{ Soybean oil } & \multicolumn{3}{|c|}{ Soybean seeds } & \multicolumn{4}{|c|}{$P$-value ${ }^{3}$} & $\begin{array}{l}\text { Extruded } \\
\text { soybeans }\end{array}$ \\
\hline v1 & $52.1^{*}$ & $54.4^{*}$ & $52.1^{*}$ & $44.6^{*}$ & $51.7^{*}$ & $47.3^{*}$ & 1.055 & $<0.01$ & $<0.01$ & 0.03 & 40.6 \\
\hline E1 & 72.2 & $77.1^{*}$ & 73.6 & 65.9 & 71.6 & $63.7^{*}$ & 1.515 & $<0.01$ & $<0.01$ & 0.20 & 69.8 \\
\hline v3 & $55.3^{*}$ & $55.6^{*}$ & $55.8^{*}$ & $53.1^{*}$ & $57.0^{*}$ & $53.3^{*}$ & 1.282 & 0.99 & 0.03 & 0.09 & 45.0 \\
\hline E3 & $79.1^{*}$ & 77.0 & $79.7^{*}$ & $83.1^{*}$ & $80.8^{*}$ & $81.9^{*}$ & 0.837 & $<0.01$ & 0.05 & 0.62 & 75.6 \\
\hline
\end{tabular}

${ }^{1}$ Six replicates for each combination of fat source and treatment.

${ }^{2} \mathrm{v} 1$ and E1 refer to the isomerization of cis-9,cis-12 C18:2 to CLA; v2 and E2 refer to the reduction of CLA to trans C18:1; v3 and E3 refer to the reduction of trans $\mathrm{C} 18: 1$ to $\mathrm{C} 18: 0$.

${ }^{3}$ Fat source $=$ unheated and roasted oils versus unheated and roasted seeds; roasting duration $=$ unheated, and 0.5 - and 6 -h roasting; interaction $=$ fat source $\times$ roasting duration

*Significantly $(P<0.05)$ different from extruded seeds (Tukey test). 
and 6 -h roasted oils and seeds. Roasting duration did not affect total CLA production or production of the different isomers assayed, but tended $(P=0.06)$ to affect cis-9,trans-11 CLA, depending on fat source (Tables 3 and 4). The total and individual trans C18:1 production were significantly affected by heating duration, with higher values for 0.5 -h roasting compared with no heating or 6 -h roasting (Tables 3 and 4).

Kinetic parameters of $\mathrm{BH}$ were also affected by roasting duration, except the efficiency of the CLA reduction (Table 5). Rate and efficiency of the first reaction (isomerization), rates of the second reaction (reduction of CLA), and of the third reaction (reduction of trans C18:1) were higher for 0.5 -h roasting than with other treatments, whereas the efficiency of the last step was lower. The second reaction (CLA reduction) was highly efficient with all treatments.

\section{Interaction Between Fat Source and Roasting Duration}

Few significant interactions existed between fat source and roasting duration, and especially regarding the disappeared quantities of cis-9,cis-12 C18:2 and cis9,cis-12,cis-15 C18:3, the percentage of disappearance of cis-9,cis-12,cis-15 C18:3 (Table 3), the production of cis-9,trans-11 CLA (Table 4), and the rates of isomerization and CLA reduction (Table 5). The lowest values of disappeared quantity were obtained with unheated seeds for cis-9,cis-12 C18:2 and its 2 first reactions of BH. For cis-9,cis-12,cis-15 C18:3, the highest disappeared quantity was for 0.5 -h roasted seeds and the lowest percentage of disappearance for 6 -h roasted seeds. The production of cis-9,trans-11 CLA was the highest for unheated oil compared with other treatments.

\section{Comparison of Extruded Seeds with Unheated and Roasted Oils and Seeds}

All 6 combinations of fat source $\times$ roasting duration were compared with extruded soybeans for all parameters (Tables 3, 4, and 5). The disappeared quantity of cis-9 C18:1 was significantly lower with extruded seeds than with oils and higher than with unheated seeds, but did not differ from roasted seeds. The percentage of disappearance of cis-9 C18:1 was higher with extruded seeds than with unheated seeds. The quantity of disappeared cis-9,cis-12 C18:2 was significantly lower with extruded seeds than with all other treatments, but the disappearance percentage of cis-9, cis-12 C18:2 was only lower than with 0.5 -h roasted oil and higher than with 6 -h roasted seeds. The quantity and percentage of $\mathrm{cis}$ 9,cis-12,cis-15 C18:3 that disappeared with extruded seeds did not differ from other treatments, except the disappeared quantity that was lower than with 0.5 -h roasted seeds and the percentage disappearance that was higher than with 6 -h roasted seeds.

The quantity of total CLA produced with extruded seeds was similar to that obtained with unheated or roasted seeds, and significantly lower than with oils (Table 3 ). This was mainly due to cis-9,trans-11 CLA and trans-9,trans-11 CLA (Table 4), as trans-10,cis-12 CLA production was not affected by extrusion. Compared with 0.5-h heated oil, extrusion resulted in lower production of most trans C18:1 isomers, except trans-5, trans-6+7+8, trans-10, and trans-11 C18:1. Extruded seeds increased production of total and trans-11 to trans-15 C18:1 isomers compared with unheated and 6-h roasted seeds, and led to trans $\mathrm{C} 18: 1$ production similar to that of 0.5 -h roasted seeds, except for trans-11 C18:1, which tended $(P=0.09)$ to be higher with extruded seeds (Table 4). The production of C18:0 was lower with extruded seeds than with roasted oils and 0.5 -h roasted seeds (Table 3 ).

The rates of the 3 reactions of cis-9,cis-12 C18:2 $\mathrm{BH}$ were lower with extruded seeds than with heated or unheated oil and seeds (Table 5). The efficiency of the first reaction (isomerization) was, in the present study, estimated by loss rate, so the values reported in Table 5 are similar to percentages of disappearance of cis-9,cis-12 C18:2 reported in Table 3, and their variations were the same. The efficiency of the second $\mathrm{BH}$ reaction (reduction of CLA) with extruded seeds was equal to those obtained with unheated or roasted seeds, and higher than with oils. The efficiency of the third reaction (reduction of trans $\mathrm{C} 18: 1$ ) was similar to that obtained with 0.5 -h roasted oil and, therefore, lower than with other treatments.

\section{DISCUSSION}

\section{Comparison of Soybean Oil with Soybean Seeds}

The effects of fat source on the amount of disappeared unsaturated $\mathrm{FA}$, at least in part, reflected a difference in FA content of fats, as oils carried greater amounts of cis-9 C18:1 and lower amounts of cis-9,cis12,cis-15 C18:3 than seeds, probably because of their different commercial origins (Table 1). For cis-9, cis-12 C18:2, the initial quantities were similar in oils and seed incubates: 68.3 versus $68.5 \mathrm{mg}$, respectively (Table 2 ). However, the quantity and the percentages of cis9,cis-12 C18:2 that disappeared were higher with oils than with seeds, in relation with better isomerization (Table 5), which also affected the disappearance percentages of cis-9 C18:1 and cis-9,cis-12,cis-15 C18:3. This was likely due to the partial protection of fat by cell membranes in seeds, delaying the availability of unsaturated FA for biohydrogenating bacteria, as pre- 
viously reported (Chilliard et al., 2000). Nevertheless, the BH capacity was high in all cultures. Previous studies reported a less efficient isomerization of cis-9,cis-12 C18:2: about $46 \%$ for oil in vitro (Troegeler-Meynadier, et al., 2006a) and about $43 \%$ for soybean seeds in situ (Troegeler-Meynadier, et al., 2006b).

Accumulation of all trans C18:1 isomers (except trans-10 C18:1), and 9,11 CLA isomers was higher with oils than with seeds. This higher accumulation of $\mathrm{BH}$ intermediates was due to higher production because of the more efficient isomerization of cis-9,cis-12 C18:2 with oils than with seeds. Indeed, CLA reduction was not inhibited with oil because of a high efficiency $(>90 \%)$ and because the reaction rate was higher with oils than with seeds (v2 $=52$ vs. $48 \mathrm{mg} / \mathrm{L}$ per hour; Table 5), suggesting an accumulation by excess of substrate coming from the first reaction and saturating the second reaction, rather than an accumulation by inhibition of the reduction. For trans C18:1 reduction, the efficiency was significantly lower with oils than with seeds ( 79 vs. $82 \%$, respectively), whereas the rate was not different (Table 5), also suggesting saturation of the third reaction in oil cultures by an excess of substrate coming from the second reaction. Such saturation of the second reductase by an excess of production of the various trans C18:1 has already been reported (TroegelerMeynadier et al., 2006a). The production of C18:0 was higher with oils than with seeds, but this resulted, in part, from the hydrogenation of cis-9 C18:1, whose content was higher in oils than in seeds. Furthermore, the higher production of C18:0 with oils supported the hypothesis of saturation of the third reaction; indeed, its production would have decreased if inhibition of the third reaction occurred.

Moreover, this saturation of the last step of $\mathrm{BH}$ in oil cultures led to an accumulation of all individual trans C18:1, except trans-10 C18:1. Similarly, no trans10,cis-12 CLA accumulated, suggesting poor efficiency of the $\Delta^{9}$-isomerization. Admittedly, our culture conditions were not favorable to promote $\Delta^{9}$-isomerization, which needs high-starch substrates (Zened et al., 2011), as opposed to our in vitro substrate that contained $67 \%$ meadow hay.

Differences between oils and seeds, although significant, were of limited extent. In the present study, $\mathrm{BH}$ was almost complete and reaction efficiencies were high, which could have masked differences between treatments.

\section{Effects of Roasting Duration on Rumen BH, and Interaction with Fat Source}

Disappearance of added unsaturated C18 FA was higher for 0.5 -h roasted than for unheated or 6 -h roast- ed oils and seeds. This slight increase of unsaturated FA BH with 0.5 -h roasted fat could be explained by partial hydrolysis of triacylglycerols in fat during shortduration heating (Kritchevsky et al., 1962). In spite of some interactions, heating of oil and seeds was not efficient to partially protect cis-9, cis-12 C18:2 from $\mathrm{BH}$, contrary to previous results (Privé et al., 2010; Kaleem et al., 2013b). In the study of Privé et al. (2010), the inhibition of sunflower oil cis-9,cis-12 C18:2 disappearance was obtained with 6 -h heating at $150^{\circ} \mathrm{C}$. In the study of Kaleem et al. (2013b), the protection of cis9,cis-12 C18:2 resulted from $150^{\circ} \mathrm{C}$ roasting for $30 \mathrm{~min}$, and no effect was observed with $110^{\circ} \mathrm{C}$-roasted seeds. Our $125^{\circ} \mathrm{C}$ roasting temperature was probably not sufficient to protect cis-9,cis-12 C18:2 from $\mathrm{BH}$ in seeds and oils. For cis-9,cis-12,cis-15 C18:3, a synergistic effect of heating duration and temperature led to the lowest percentage of disappearance for 6 -h roasted seeds. In the study of Kaleem et al. (2013b), the percentage of disappearance of cis-9,cis-12,cis-15 C18:3 was already decreased from $110^{\circ} \mathrm{C}$ heating. Indeed cis-9, cis-12, cis-15 C18:3 is more sensitive to oxidation than cis-9,cis-12 C18:2 and, in seeds, protection of PUFA against BH would be linked to aldehydes (end oxidation products), which are able to complex with proteins also contained in seeds, but not in oil.

The cis-9,trans-11 CLA production was affected differently by roasting duration, depending on fat source: roasting of seeds did not modify it, whereas 6-h roasting of oil led to lower production of cis-9,trans-11 CLA than unheated oil (Table 3). Similarly, Kaleem et al. (2013b) did not observe an effect of soybean roasting on CLA production. Privé et al. (2010) also noticed a decrease in cis-9,trans-11 CLA production with their 6-h heated oil compared with unheated oil, due to inhibition of $\Delta^{12}$-isomerization. In the present study, estimation of kinetic parameters did not reveal any effect of 6 -h heating on cis-9,cis-12 C18:2 isomerization compared with unheated oil, and 0.5-h heating increased it. In fact, the lower production of cis-9,trans-11 CLA observed with 6-h roasted oil was associated with a higher production of C18:0 compared with unheated oil, suggesting more complete $\mathrm{BH}$. The efficiency of the last $\mathrm{BH}$ reaction was $3 \%$ lower with 0.5 -h roasted fat than other unroasted or roasted fats, without modification of the reaction rate. Hence, the increase in trans $\mathrm{C} 18: 1$ production was probably due to saturation of the third reaction because of higher isomerization of cis-9,cis-12 C18:2. This was confirmed by the higher production of C18:0 obtained with 0.5 -h roasted fat compared with the other fats.

In the present study, trans-10 isomer production was increased by 0.5 -h roasting due to trans-10 C18:1, which was increased similar to other trans C18:1 with 0.5-h roasting. Contrary to the study of Privé et al. 
(2010), who observed increased production of trans-10 isomers with 6 -h, $150^{\circ} \mathrm{C}$ heated oils, our 6 -h roasted oil did not increased trans-10 C181 compared with unheated oil. In the present experiment, 6 -h seed roasting did not increase trans-10 isomer production, as previously observed by Kaleem et al. (2013b). The increase in trans-10 isomer production with heated fat would be due to hydroperoxides (Kaleem et al., 2013a), which were much more abundant in the study of Privé et al. (2010) than in the present experiment (238 and less than $56 \mathrm{mEq}$ of $\mathrm{O}_{2} / \mathrm{kg}$ of heated oil, respectively).

The production of trans-11 isomers has been proven to be dependent on oxidative products generated by heating, and a decrease in their production was observed with high PV (i.e., $238 \mathrm{mEq}$ of $\mathrm{O}_{2} / \mathrm{kg}$ of heated oil in vitro; Privé et al., 2010) and $240 \mathrm{mEq}$ of $\mathrm{O}_{2} / \mathrm{kg}$ of oil in vivo (Vázquez-Añón et al., 2008). In the present experiment, fats exhibited lower PV values $(<10$ $\mathrm{mEq}$ of $\mathrm{O}_{2} / \mathrm{kg}$ of fat) for unheated and 0.5 -h roasted fat sources, and around $50 \mathrm{mEq}$ of $\mathrm{O}_{2} / \mathrm{kg}$ of fat for 6-h roasted fat sources. A $50 \mathrm{mEq}$ of $\mathrm{O}_{2} / \mathrm{kg} \mathrm{PV}$ was probably not sufficient to provoke a marked inhibition of trans-11 isomer production. Kaleem et al. (2013b) showed no evidence of an effect of seeds roasting on trans-11 isomer production. In the present study, the production of total trans-11 isomers followed the same trends as that of trans-11 C18:1, and was increased with 0.5 -h roasted fat, because of more efficient isomerization.

\section{Comparison of Unheated and Roasted Oils and Seeds with Extruded Seeds}

Extrusion is known to alter vegetal cell walls and, thus, to release fat. These released fats are more sensitive to oxidation than fat remaining in cells, which explains why extruded seeds had a higher PV than 0.5$\mathrm{h}$ roasted seeds in spite of a shorter thermal treatment (Table 1).

The disappeared quantities and rates of $\mathrm{BH}$ reactions of unsaturated FA were lower with extruded seeds than with other fat sources, which could be explained by the difference in the initial quantities of these FA, probably due to a loss of FA during extrusion.

Nevertheless, the percentages of disappearance of unsaturated FA with extruded seeds were not different from that observed with unheated seeds (Table 3), indicating that extrusion in the present conditions did not protect unsaturated $\mathrm{FA}$ from $\mathrm{BH}$, in agreement with previous studies (Chouinard et al., 1997a; Gonthier et al., 2005). Nevertheless, some studies reported a decrease in BH with extrusion (Reddy et al., 1994; Chouinard et al., 1997b; Troegeler-Meynadier et al., 2006b). An explanation for protection of PUFA from
BH in heated seeds was a possible link between aldehydes generated by lipid oxidation during heating and proteins contained in seeds (Kaleem et al., 2013b). Those authors noticed that a high heating temperature $\left(150^{\circ} \mathrm{C}\right)$ was necessary to produce enough aldehydes to protect cis-9, cis-12 $\mathrm{C} 18: 2$ from $\mathrm{BH}$ when $110^{\circ} \mathrm{C}$ heating was not sufficient to induce such protection. In our study, the $125^{\circ} \mathrm{C}$ extrusion temperature was probably not high enough to provide protection of PUFA against $\mathrm{BH}$.

As a whole, extruded seeds led to FA balances that were intermediate between oils and seeds. Similar results were previously observed for milk FA with linseed, with effects of extruded linseed on milk FA profile being intermediate between those of raw linseed and linseed oil, or similar to linseed oil (Chilliard et al., 2009). For disappearance of unsaturated FA, extrusion led to values numerically similar to those of 0.5 -h roasted seeds, lower than 0.5-h roasted oil, and higher than 6-h roasted seeds.

With extruded seeds, the production of total CLA, cis-9,trans-11 CLA, and trans-9,trans-11 CLA was similar to that obtained with unheated or roasted seeds, and lower than with unheated or roasted oils. The trans-10,cis-12 CLA production was not modified by extrusion. Troegeler-Meynadier et al. (2006b) and Doreau et al. (2009) showed that extruded oilseeds enhanced CLA production, but with a higher extrusion temperature for the first study $\left(140-150^{\circ} \mathrm{C}\right)$ and a longer preconditioning period for the later $(157 \mathrm{~min}$ at $72^{\circ} \mathrm{C}$, followed by extrusion at $120^{\circ} \mathrm{C}$ ). These treatments could have increased fat release, underlying the importance of conditions of the extrusion process.

The total trans $\mathrm{C} 18: 1$ production in cultures with extruded seeds was higher than with unheated or 6 -h roasted seeds; this was the case for most individual trans C18:1 isomers, except trans-10 C18:1, and only trans-11 C18:1 production tended to be higher $(P=0.08)$ with extrusion than with 0.5 -h roasted seeds. Other studies also mainly observed an increase in trans C18:1 with extruded seeds compared with raw seeds (Gonthier et al., 2005), in particular for trans-11 C18:1 (Chouinard et al., 1997a,b). As for 0.5-h roasted oil, extrusion led to lower efficiency of the last reaction compared with other fat, which could explain the greater accumulation of trans-11 C18:1 observed with extruded seeds than with unheated and roasted seeds, based on cis-9,cis-12 C18:2 initial quantities: $10.7 \mathrm{mg}$ of trans- $11 \mathrm{C} 18: 1$ produced from $55.8 \mathrm{mg}$ of initial cis-9,cis-12 C18:2 with extruded seeds (i.e., a ratio of 0.19 ), and $9.1 \mathrm{mg}$ of trans $-11 \mathrm{C} 18: 1$ produced from $69.0 \mathrm{mg}$ of initial cis-9,cis-12 C18:2 for unheated and roasted seeds, on average (i.e., a ratio of 0.13). Hence, the effects of extrusion could be linked, in part, to better availability of fat because of the rupture 
of cell membranes caused by this process and, in part, to partial hydrolysis of triacylglycerols in fat during short-duration heating. That is why $\mathrm{BH}$ in extruded seeds was intermediate between oils and 0.5 -h roasted soybeans. More cis-9,cis-12 C18:2 was available for $\mathrm{BH}$ than in 0.5 -h roasted soybeans, leading to a greater accumulation of trans C18:1, but less than in oils, leading to a lower accumulation of CLA. Indeed, the third reaction is easier to saturate than the second because fewer effector bacteria exist (Paillard et al., 2007) and the second reductase would be less effective than the first one (Troegeler-Meynadier et al., 2006a).

Extrusion did not promote trans-10 isomer production. Such an observation was not yet reported because some studies relative to effects of extrusion did not separate trans-10 from trans-11 isomers (Chouinard et al., 1997a,b; Troegeler-Meynadier et al., 2006b) and others (Gonthier et al., 2005; Doreau et al., 2009) used linseeds, with a high proportion of cis-9,cis-12,cis-15 C18:3, which is not a precursor of trans-10 isomers (Zened et al., 2011).

\section{CONCLUSIONS}

Soybean oil was more efficient than seeds in producing CLA, and to a lesser extent trans C18:1, in particular trans-11 isomers, because accessibility of triacylglycerols to microbes is not hampered by vegetal cells. Heating conditions (i.e., duration and nature of the process) affected $\mathrm{BH}$. A $125^{\circ} \mathrm{C}, 0.5$-h roasting resulted in a high isomerization efficiency, probably due to partial hydrolysis of triacylglycerols, making FA directly available for bacteria isomerases, leading to high trans C18:1 production, in particular trans-11 C18:1. Extrusion of seeds had intermediate effects between 0.5 -h roasting of seeds and oil, leading to higher trans-11 C18:1 accumulation than roasted seeds, but similar to oil, and to lower cis-9,trans-11 CLA accumulation than oils, but similar to seeds. This effect could be linked to the lower quantitative capacity of the second reduction compared with CLA reduction, leading to rapid saturation of the second reduction when isomerization increased, whereas CLA reduction remained efficient. In conclusion, our results confirm that extrusion of seeds is the most efficient thermal treatment to optimize CLA in ruminants. Further studies are warranted to evaluate the effects of extrusion conditions on $\mathrm{BH}$.

\section{REFERENCES}

Abdi, E., F. Fatahnia, M. Dehghan Banadaki, A. Azarfar, and A. Khatibjoo. 2013. Effects of soybeans roasting and monensin on milk production and composition and milk fatty acids profile of lactating dairy cows. Livest. Sci. 153:73-80.

AFNOR (Association Française de Normalisation). 2004. Détermination de l'indice peroxyde. Corps gras d'origines animale et végé- tale. In Collection de Normes Françaises et de Méthodes Communautaires. Aliments des Animaux. Méthodes d'Analyse. AFNOR ISO 3960. AFNOR, Paris, France.

Akraim, F., M. C. Nicot, P. Weil, and F. Enjalbert. 2006. Effects of preconditioning and extrusion of linseed on the ruminal biohydrogenation of fatty acids. 1. In vivo studies. Anim. Res. 55:83-91.

Chilliard, Y., A. Ferlay, R. M. Mansbridge, and M. Doreau. 2000 Ruminant milk fat plasticity: Nutritional control of saturated, polyunsaturated, trans and conjugated fatty acids. Ann. Zootech. 49:181-205.

Chilliard, Y., C. Martin, J. Rouel, and M. Doreau. 2009. Milk fatty acids in dairy cows fed whole crude linseed, extruded linseed, or linseed oil, and their relationship with methane output. J. Dairy Sci. 92:5199-5211.

Chouinard, P. Y., V. Girard, and G. J. Brisson. 1997a. Performance and profiles of milk fatty acids of cows fed full fat, heat-treated soybeans using various processing methods. J. Dairy Sci. 80:334342.

Chouinard, P. Y., J. Levesque, V. Girard, and G. J. Brisson. 1997b. Dietary soybeans extruded at different temperatures: Milk composition and in situ fatty acid reactions. J. Dairy Sci. 80:2913-2924.

Doreau, M., S. Laverroux, J. Normand, G. Chesneau, and F. Glasser. 2009. Effect of linseed fed as rolled seeds, extruded seeds or oil on fatty acid rumen metabolism and intestinal digestibility in cows. Lipids 44:53-62.

Gonthier, C., A. F. Mustafa, D. R. Ouellet, P. Y. Chouinard, R. Berthiaume, and H. V. Petit. 2005. Feeding micronized and extruded flaxseed to dairy cows: Effects on blood parameters and milk fatty acid composition. J. Dairy Sci. 88:748-756.

Griinari, J. M., B. A. Corl, S. H. Lacy, P. Y. Chouinard, K. V. V. Nurmela, and D. E. Bauman. 2000. Conjugated linoleic acid is synthesized endogenously in lactating dairy cows by $\Delta^{9}$-desaturase. J. Nutr. 130:2285-2291.

Jenkins, T. C. 2010. Technical note: Common analytical errors yielding inaccurate results during analysis of fatty acids in feed and digesta samples. J. Dairy Sci. 93:1170-1174.

Kaleem, A., F. Enjalbert, Y. Farizon, and A. Troegeler-Meynadier. 2013a. Effect of chemical form, heating, and oxidation products of linoleic acid on rumen bacterial population and activities of biohydrogenating enzymes. J. Dairy Sci. 96:7167-7180.

Kaleem, M., Y. Farizon, F. Enjalbert, and A. Troegeler-Meynadier. 2013b. Lipid oxidation products of heated soybeans as a possible cause of protection from ruminal biohydrogenation. Eur. J. Lipid Sci. Technol. 115:161-169.

Kritchevsky, D., S. A. Tepper, and J. Langan. 1962. Influence of shortterm heating on composition of edible fat. J. Nutr. 77:127-130.

McNiven, M. A., J. Duynisveld, E. Charmley, and A. Mitchell. 2004 Processing of soybean affects meat fatty acid composition and lipid peroxidation in beef cattle. Anim. Feed Sci. Technol. 116:175184.

Mosley, E. E., G. L. Powell, M. B. Riley, and T. C. Jenkins. 2002. Microbial biohydrogenation of oleic acid to trans isomers in vitro. J. Lipid Res. 43:290-296.

Neves, C. A., G. T. Santos, M. Matsushita, E. M. Alves, R. L. Oliveira, A. F. Branco, D. C. Silva, A. C. Furlan, and H. V. Petit. 2007. Intake, whole tract digestibility, milk production and milk composition of Holstein cows fed extruded soybeans treated with or without lignosulfonate. Anim. Feed Sci. Technol. 134:32-44.

Paillard, D., N. McKain, L. C. Chaudhary, N. D. Walker, F. Pizette, I Koppova, N. R. McEwan, J. Kopečný, P. E. Vercoe, P. Louis, and R. J. Wallace. 2007. Relation between phylogenic position, lipid metabolism and butyrate production by different Butyrivibrio-like bacteria from the rumen. Antonie van Leeuwenhoek 91:417-422.

Privé, F., S. Combes, L. Cauquil, Y. Farizon, F. Enjalbert, and A. Troegeler-Meynadier. 2010. Temperature and duration of heating of sunflower oil affect ruminal biohydrogenation of linoleic acid in vitro. J. Dairy Sci. 93:711-722.

Reddy, P. V., J. L. Morrill, and T. G. Nagaraja. 1994. Release of free fatty acids from raw or processed soybeans and subsequent effects on fiber digestibilities. J. Dairy Sci. 77:3410-3416. 
Sukhija, P. S., and D. L. Palmquist. 1988. Rapid method for determination of total fatty acid content and composition of feedstuffs and feces. J. Agric. Food Chem. 36:1202-1206.

Troegeler-Meynadier, A., L. Bret-Bennis, and F. Enjalbert. 2006a. Rates and efficiencies of reactions of ruminal biohydrogenation of linoleic acid according to $\mathrm{pH}$ and polyunsaturated fatty acids concentrations. Reprod. Nutr. Dev. 46:713-724.

Troegeler-Meynadier, A., and F. Enjalbert. 2005. Les acides linoléiques conjugués: 1. Intérêts biologiques en nutrition. Rev. Méd. Vét. 156:207-216.

Troegeler-Meynadier, A., M. C. Nicot, and F. Enjalbert. 2006b. Effects of heating process of soybeans on ruminal production of conjugated linoleic acids and trans-octadecenoic acids in situ. Rev. Méd. Vét. 157:509-514.
Troegeler-Meynadier, A., M. C. Nicot, and F. Enjalbert. 2007. Effects of fat source and dietary sodium bicarbonate plus straw on the conjugated linoleic acid (CLA) content of milk of dairy cows. Arch. Anim. Nutr. 61:406-415.

Vázquez-Añón, M., J. Nocek, G. Bowman, T. Hampton, C. Atwell, P. Vázquez, and T. Jenkins. 2008. Effects of feeding a dietary antioxidant in diets with oxidized fat on lactation performance and antioxidant status of the cow. J. Dairy Sci. 91:3165-3172.

Zened, A., A. Troegeler-Meynadier, M. C. Nicot, S. Combes, L. Cauquil, Y. Farizon, and F. Enjalbert. 2011. Starch and oil in the donor cow diet and starch in substrate differently affect the in vitro ruminal biohydrogenation of linoleic and linolenic acids. J. Dairy Sci. 94:5634-5645. 